\title{
Long-term behavioral restriction and adult behavior in the rat*
}

\author{
R. L. RUSSELL and R. O. PIHL \\ McGill University, Montreal, Quebec, Canada
}

Four hooded rats were raised from Day 10 through Day 221 of life in a cage which prevented rearing responses and modified certain grooming responses. Only slight transient differences in the forms of these behaviors were observed when these restricted Ss were compared to normally raised controls in free-field situations. The results were interpreted as meaning that prolonged response prevention is not sufficient to prevent the development of species-specific behavior patterns.

Differing periods of restricted sensory input early in life produce in adulthood proportionate disruptions of both behavior and physiology in a wide variety of organisms (Melzack, 1968; Riesen, 1961; Thompson \& Grusec, 1970). By contrast, the prevention of performance of a species-specific behavior pattern until after the age at which it appears spontaneously generally produces only transient effects (Dennis, 1941; McGraw, 1946). The restricted behavior appears in normal form following a short period of practice. These latter findings are limited by the fact that the period of restriction usually ended shortly after the normal time of appearance of the behavior pattern. Perhaps the disruption would be more marked if the restriction period were extended. The present study constitutes an attempt to modify the forms of rearing and grooming behavior patterns in the rat by imposing physical restrictions on these patterns early in life and continuing them long into adulthood.

\section{METHOD}

The Ss were the seven male and six female offspring of a single litter of a 150-day-old hooded rat of the Royal Victoria strain. This female raised the Ss, from parturition through Day 10 of the offsprings' lives, under normal laboratory conditions in a $13 \times 15 \times 6$ in. plastic cage containing pine shavings and paper nesting material. The experiment was begun on the 11 th day, when the female was removed. The litter was split and half of the offspring were placed into each of two living cages for the duration of the experiment. Each of these cages measured $12 \times 18 \times 10$ in., had a wire mesh floor, wood sides and back, and a Plexiglas front. A Plexiglas top slid into grooves cut into the sides and back, making the distance from the floor to the top adjustable from 1 to $10 \mathrm{in.}$ in $1 / 4$-in. steps.

One cage contained the four male and three female Ss assigned to the experimental group. The distance between the floor and top of this box was always sufficient to permit the Ss relatively unimpeded horizontal movement but prevented rearing or sitting upon the haunches. The second cage contained the three male and three female Ss assigned to the control group. The distance

*This research was supported in part by Grant APA-201 from the National Research Council of Canada. Dalbir Bindra is sponsor of this manuscript and takes full editorial responsibility. between the top ani floor of this cage always per litted unimpeded vertical and horizontal movement.

Using an eyedropper, E hand-fed all Ss during the first few days of the experiment. Ss were fed every $3 \mathrm{~h}$ from 9:00 a.m. to 11:00 p.m. During hand-feeding, each $S$ was held by $E$ in order to prevent rearing and grooming. A mixture of evaporated milk, water, and pablum constituted the diet during this time. This food was supplemented first by wet mash and later by dry food and water available ad lib. As the Ss showed increasing ability to care for themselves, $E$ decreased the number of daily feedings. Ss ate only dry food after Day 24 of life.

All Ss were observed and videotaped in their living cages on the 221st day of life. On the 222nd day, each $S$ was given a 3 -min trial in a testing box, during which the latency to the first rear and frequency of rearing responses were recorded. A rearing response was scored whenever a $S$ lifted its forelegs and paws free of any horizontal surface for $1 \mathrm{sec}$ or longer. This testing box measured $18 \times 18 \times 16$ in. and had a wood back, sides, and floor, and a Plexiglas front. The top was open. A $6 \times 8$ in. platform was mounted 6 in. off the floor at the center of the rear wall. On the following day, the Ss in the experimental group, all 23-h water deprived, were placed together for $1 \frac{1}{2} \mathrm{~h}$ in the testing box, modified by removing the platform and suspending a water bottle in the center of the top of the box, with the tip of the spout 7 in. off the floor. In both tests, E videotaped sequences of the S's behavior and noted the postures taken during rearing and grooming behavior.

\section{RESULTS AND DISCUSSION}

Three Ss in the experimental group and two in the control group died before the end of the hand-feeding period. The others survived through the end of the experiment. Each group contained one male and three female $S s$ at the time of testing.

On the first day, the median latencies to rear and frequencies of rearing for the experimental and control groups, respectively, were 20 and $14 \mathrm{sec}$ and 19 and 17 rearing responses. Neither measure achieved statistical significance (Mann-Whitney Us $=4$ and $7, \mathrm{ps}=.17$ and .44 , respectively). E noted that $S$ s in the experimental group always placed their forepaws against vertical surfaces while rearing in the first test. During the second day of testing, however, these Ss showed themselves to be fully capable of rearing to full height without such aid in order to drink. They appeared somewhat unsteady and tended to overcorrect errors in balance. This unsteadiness decreased over the course of the test session.

Direct observation of the Ss and detailed examination of the videotape indicated that, in the living cages, the components of grooming normally labeled face washing and scratching (Bolles \& Woods, 1964) were performed identically by Ss in both groups. The component of grooming labeled fur licking or biting was modified extensively in the experimental group, as this form of grooming normally occurs while $S$ sits on its haunches. Ss in the experimental group were observed to groom both their dorsal and ventral surfaces while lying upon their sides. 
When observed in the testing box, Ss in the experimental group exhibited grooming sequences resembling both their own behavior in the living cage and the behavior of the control Ss. Both types of behavior were observed in the same Ss.

These findings lend strength to the principle that species-specific behavior patterns are not eliminated or modified in an organism that has been reared in circumstances which prevent its exhibiting and practicing those behaviors at the normal age. Furthermore, the organism retains the ability to perform these behaviors, even when the restriction period ends late in life.

\section{REFERENCES}

Bolles, R. C., \& Woods, P. J. The ontogeny of behavior in the albino rat. Animal Behavior, 1964, 12, 427-441.

Dennis, W. Infant development under conditions of restricted practice and of minimum social stimulation. Genetic Psychology Monographs, 1941, 23, 143-191.

McGraw, M. B. Maturation of behavior. In L. Carmichael (Ed.), Manual of child psychology. New York: Wiley, 1946.

Melzack, R. Early experience: A neuropsychological approach to heredity-environment interactions. In $G$. Newton and $S$. Levine (Eds.), Early experience and behavior. Springfield, Ill: Thomas, 1968

Riesen, A. H. Stimulation as a requirement for growth and function in behavioral development. In D. W. Fiske and S. R. Maddi (Eds.), Functions of varied experience. Homewood, Ill: Dorsey, 1961.

Thompson, W. R., \& Grusec, J. Studies of early experience. In P. H. Mussen (Ed.), Manual of child psychology. 3rd ed. New York: Wiley, 1970.

(Received for publication October 31, 1972.) 